\title{
A IMPORTÂNCIA DOS JOGOS PARA O ENSINO DE ARITMÉTICA EM MANUAIS DE AUTORIA DE THEOBALDO MIRANDA SANTOS
}

\author{
Cintia Schneiderl \\ David Antonio da Costa ${ }^{2}$
}

\section{RESUMO}

Neste artigo, tem-se por objetivo, compreender o papel dos jogos para o ensino de aritmética, nos manuais pedagógicos 'Noções de didática especial', 'Metodologia do ensino primário', 'Manual do professor primário' de autoria de Theobaldo Miranda Santos, dois destes, publicados nos anos de 1960 e outro em 1952. As análises utilizam aportes da história cultural (CHARTIER, 2010), privilegiando os manuais pedagógicos como fonte de pesquisa (VALENTE, 2008; CHOPPIN, 2009), além dos demais aportes da própria história da educação matemática e ainda Moura (1999) e Mattos (2009), como referencial, no que diz respeito aos jogos para o ensino de aritmética. Theobaldo Miranda Santos foi um importante autor, responsável pela publicação de muitos manuais pedagógicos e sua figura torna-se mais relevante ainda, quando se trata do embate entre católicos e escolanovista em meados do século passado. Quanto aos jogos, Santos indica seu uso, porém sem citar, especificamente, determinado jogo ou apresentar um tutorial. Santos demonstra-se confuso ao definir seu posicionamento quanto aos jogos, porém, vêse a homogeneidade, nos três manuais, ao afirmar que os jogos são meio de tornar a aritmética mais interessante, divertida e contextualizada com o dia a dia dos alunos.

Palavras-chave: Jogos para o ensino de aritmética. Manuais pedagógicos. História da educação matemática.

\section{THE IMPORTANCE OF GAMES FOR TEACHING ARITHMETIC IN MANUALS WRITTEN BY THEOBALDO MIRANDA SANTOS}

\footnotetext{
'Professora no Instituto Federal Catarinense - Câmpus Concórdia. Mestra em Educação Científica e Tecnológica pela Universidade Federal de Santa Catarina. Pesquisadora do Grupo de Pesquisa em História da Educação Matemática - GHEMAT. E-mail: cintia.schneider1995@gmail.com

2 Professor do Departamento de Metodologia de Ensino de Centro de Ciências da Educação da Universidade Federal de Santa Catarina. Doutor em Educação Matemática. Email: david.costa@ufsc.br
} 


\section{ABSTRACT}

This paper aims to understand the role of games for the teaching of arithmetic in the pedagogical manuals 'Notions of special didactics', 'Methodology of primary education', 'Manual of the primary teacher' authored by Theobaldo Miranda Santos, two of these manuals were published in the years 1960 and 1952. The analyzes use contributions of cultural history (CHARTIER, 2010) privileging the pedagogical manuals as sources of research (VALENTE, 2008; CHOPPIN, 2009), besides other contributions of the history of mathematics education, and Moura (1999) and Mattos (2009) as a reference with regard to games for the teaching of arithmetic. Theobaldo Miranda Santos was an important author, responsible for the publication of many pedagogical manuals and his figure becomes even more relevant when it comes to the clash between Catholicism and Escolanovismo in the middle of the last century. As for the games, Santos indicates their use, but without specifically mentioning a given game or presenting a tutorial. Santos is confused in defining his position regarding games, however, we can see the homogeneity in all three manuals, as they state that games are a way to make arithmetic more interesting, fun and sensitive to the students' daily lives.

Keywords: Games for teaching arithmetic. Teaching manuals. History of mathematics education.

\section{LA IMPORTANCIA DE LOS JUEGOS PARA ENSEÑAR ARITMÉTICA EN LOS MANUALES ESCRITOS POR THEOBALDO SANTOS MIRANDA}

\section{RESUMEN}

El propósito de este artículo es comprender el papel de los juegos para la enseñanza de la aritmética en los manuales pedagógicos 'Noções de didática especial', 'Metodologia do Ensino primário', 'Manual do professor primário' de Theobaldo Miranda Santos, publicados en los años de 1960, 1952 y 1960, respectivamente. Los análisis utilizan aportes de la historia cultural (CHARTIER, 2010) privilegiando los manuales pedagógicos como fuente de investigación (VALENTE, 2008; CHOPPIN, 2009), además de los demás aportes de la propia historia de la educación matemática como así también de Moura (1999) y Mattos (2009) como referencia en lo que respecta a los juegos para la enseñanza de aritmética. Theobaldo Miranda Santos fue un importante autor, responsable por la publicación de muchos manuales pedagógicos y su figura se vuelve aún más relevante, cuando se trata del embate entre católicos y escolanovistas a mediados del siglo pasado. En cuanto a los juegos, Santos indica su uso, pero sin citar, específicamente, determinado juego o presentar un tutorial. Santos se demuestra confuso al definir su posicionamento en cuanto a los juegos, sin embargo se puede ver la homogeneidad, en los tres manuales, al afirmar que los juegos son un medio de volver la aritmética más interesante, divertida y contextualizada con el cotidiano de los alumnos.

Palabras clave: Juegos para la enseñanza de la aritmética. Manuales de enseñanza. Historia de la educación de las matemáticas. 


\section{CONSIDERAÇÕES INICIAIS}

O presente artigo faz parte de uma pesquisa maior, no âmbito de mestrado, denominada 'Jogos para o ensino de aritmética em manuais pedagógicos de 1930-1960 no Brasil'3, defendida no ano de 2017, no Programa de Pós-Graduação em Educação Científica e Tecnológica, da Universidade Federal de Santa Catarina - UFSC. Nesta pesquisa, foram analisados 14 manuais pedagógicos de sete autorias diferentes, e neste artigo, tem-se por objetivo, analisar três manuais de autoria de Theobaldo Miranda Santos, procurando compreender o papel dos jogos para o ensino de aritmética. Para isso, será mencionada a trajetória pessoal e profissional do autor, visto que, isso por vezes, justifica escolhas na escrita dos manuais. Além disso, a editora responsável pela publicação dos manuais também será analisada.

Este artigo, bem como, a pesquisa maior, está inserido no campo da História da educação matemática ${ }^{4}$. Para Valente (2007, p. 4), a história é construída sobre fatos, mas esses fatos não estão 'prontos', "[...] não haverá fatos sem questões prévias para o seu estabelecimento. Em síntese, não existem fatos históricos sem questões postas pelo historiador". Ressaltando que os fatos são os que o pesquisador constrói com base em suas fontes de investigação, pontuando que uma mesma fonte pode ser usada em pesquisas diferentes, variando de acordo com a pergunta feita a ela. Além disso, os fatos são erigidos nos vestígios deixados nas fontes e somente falarão se forem interrogados de acordo com o objetivo do pesquisador.

\footnotetext{
3 Disponível em: <https://repositorio.ufsc.br/handle/123456789/181816>. Acesso em: 18.jul.2018

${ }^{4}$ Valente (2013, p. 24), distingue 'Educação Matemática' de 'educação matemática'. A primeira expressão designa o recente campo acadêmico, lugar de investigações sobre ensino e aprendizagem da Matemática. Uma referência fundadora, no Brasil, desse campo pode ser dada pela criação da SBEM - Sociedade Brasileira de Educação Matemática, no ano de 1988. A segunda expressão remete aos processos de ensino e aprendizagem da Matemática desde tempos imemoriais, constituindo-se, assim, em tema de pesquisa dos estudos relativos à história da educação matemática. De todo modo, a distinção se faz necessária para que não se pense que por 'história da educação matemática' estivessem apenas alocados os estudos pós-anos 1980, ou mesmo restritos à história do campo de pesquisa.
} 
Nos últimos tempos, percebe-se um avanço significativo no aumento das pesquisas na área da História da educação matemática. Esse fato é apontado por Gomes:

Um exemplo do crescimento das pesquisas em História da Educação Matemática, fácil de ser identificado, encontra-se nas edições anuais do Encontro Brasileiro de Estudantes de Pós-graduação em Educação Matemática (EBRAPEM) realizadas no período 2003-2008, que passaram a incluir, como um de seus eixos temáticos, com a inscrição de um número significativo de trabalhos, a História da Educação Matemática (GOMES, 2016, p. 7).

A participação no GHEMAT - Grupo de Pesquisa de História da Educação Matemática do Brasil $^{5}$ e do GHEMAT/SC $^{6}$ possibilitou expandir os conhecimentos sobre o que é estudar história da educação matemática, bem como, compreender a metodologia de trabalho utilizada pelos pesquisadores dessa linha, pois como dito por Valente (2007, p. 47) o grupo tem por intenção "[...] alargar o entendimento de como se dá, na história, o processo de escolarização dos saberes e, em particular, da matemática, a partir de um instrumental teórico metodológico utilizado por historiadores". O GHEMAT destaca-se por desenvolver, coletivamente, projetos temáticos de pesquisa na área da história da educação matemática, em diversos segmentos, como por exemplo: dos conteúdos escolares, dos livros didáticos, da história do ensino de matemática, da disciplina Matemática e da formação de professores.

\footnotetext{
5 Na página online do GHEMAT Brasil (http://www2.unifesp.br/centros/ghemat/paginas/about_ghemat.htm), encontram-se mais informações de que foi criado no ano de 2000 e é liderado pelos professores Wagner Rodrigues Valente da UNIFESP (Universidade Federal de São Paulo) e Neuza Bertoni Pinto, vinculada a REAMEC (Rede Amazônica de Educação em Ciências e Matemática) e está credenciado no diretório de Grupos de Pesquisa do CNPq. O grupo reúne pesquisadores de variadas universidades e estados brasileiros, mais precisamente, de acordo com levantamento 5 realizado em 2016, são 35 pesquisadores e 87 estudantes, sendo estes estudantes de mestrados profissionalizantes e acadêmicos, doutorados e alunos de graduação.

6 O GHEMAT - SC foi institucionalizado no segundo semestre de 2017 e tem como líder o professor Dr. David Antonio da Costa e vice-líder a professora Dra. lara Zimmer. Atualmente conta com sete pesquisadores, entre eles alunos de graduação, mestrado e doutorado da UFSC. Disponivel em: <http://dgp.cnpq.br/dgp/espelhogrupo/2464392240898492>. Acesso em 25 jul.2017.
} 
Exatamente por conta dessa característica de produção coletiva que o GHEMAT utiliza-se constantemente do Repositório de Conteúdo Digital RCD "[...] para armazenar documentação vinda de diferentes partes do país, com a finalidade de subsidiar estudos sobre história da educação matemática brasileira" 7. O RCD está situado, 'fisicamente', na Universidade Federal de Santa Catarina, no qual, são alocados diversos documentos (livros, legislações, cadernos, revistas...) encontrados por pesquisadores do GHEMAT de todo Brasil. Essa base de documentos, disponível por acesso aberto pela internet, tem se mostrado profícua na realização de estudos histórico-comparativos relativos à circulação de modelos pedagógicos, permitindo o estabelecimento do diálogo entre os pesquisadores nos seus diversos locais de pesquisa (COSTA; VALENTE, 2015).

Certeau cita que, em pesquisas históricas os conteúdos a serem pesquisados são as fontes, ainda que:

Em história, tudo começa com o gesto de separar, de reunir, de transformar em "documentos" certos objetos distribuídos de outra maneira. Esta nova distribuição cultural é o primeiro trabalho. Na realidade ela consiste em produzir tais documentos, pelo simples fato de recopiar, transcrever ou fotografar estes objetos mudando ao mesmo tempo o seu lugar e o seu estatuto (CERTEAU, 2013, p. 50).

No âmbito das pesquisas em história da educação matemática, podese considerar que os documentos presentes nas escolas despertam o interesse dos pesquisadores, que buscam compreender o processo de escolarização em outros tempos. Historiadores da educação matemática não veem a história sob uma ótica positivista que busca uma explicação do que aconteceu no passado, "A história [defendida pelos pesquisadores] pretende dar uma representação adequada da realidade que foi e já não é" (CHARTIER, 2010, p. 24).

Ainda sob a visão da História Cultural, Chartier (2010) afirma que o material impresso é um objeto primordial de investigação e é preciso

\footnotetext{
7 Excerto retirado da página do GHEMAT, disponível em: < http://www2.unifesp.br/centros/ghemat/paginas/about_ghemat.htm>. Acesso em: 22 out.2016.
} 
considerar como as pessoas fazem uso destes objetos e como eles são difundidos, ou seja, considerar as influências que este documento recebia e contexto em que foi produzido e difundido.

Os manuais pedagógicos podem ser chamados de livros didáticos, ou ainda, livros do professor. Mas, independente da sua nomeação, eles fazem parte da chamada cultura escolar. Esta é definida por Julia como:

[...] um conjunto de normas que definem os saberes a ensinar e os comportamentos a inculcar, e um conjunto de práticas que permitem a transmissão e a assimilação de tais saberes e a incorporação destes comportamentos (JULIA, 2001, p. 10).

Sendo esta cultura escolar, segundo Viñao Frago (2007), não somente aquilo que se adquire na escola, mas tudo aquilo que não pode ser adquirido em outro lugar que não fosse a escola, além de caracterizá-la como algo que permanece e dura.

Expõe-se que a busca pelos manuais pedagógicos, publicados no recorte temporal de 1930 a 1960, foi realizada em bibliotecas, acervos, arquivos públicos e especialmente no RCD. Tratando-se, especificamente, da análise, na pasta dos livros didáticos e manuais pedagógicos presentes no Repositório aferiu-se que, dos 406 exemplares, 149 são datados de 1930 a 1960, dos quais, 18 títulos possuem indicações de jogos para o ensino de aritmética (exemplares editados no Brasil): 02 são livros didáticos e 16 manuais pedagógicos. Para este artigo, dos 16 manuais pedagógicos, optou-se por três de autoria de Theobaldo Miranda Santos, visto sua notoriedade e a forma como os manuais foram redigidos e os jogos para o ensino de atirmética foram citados. Aponta-se que, a escolha por manuais pedagógicos (e não pelos livros didáticos) deu-se visto a influência dos manuais na formação dos professores e/ou no planejamento e trabalho destes docentes.

Considerando os preceitos de Chartier, sobre a importância de se considerar o contexto de produção do material, aponta-se que o autor no manual a ser analisado, Theobaldo Miranda Santos foi um importante nome 
no que diz respeito a autorias de manuais pedagógicos e, principalmente, por ser um autor 'católico'8 que buscou adequar os preceitos escolanovistas, a um modelo de pedagogia católica. Optou-se pela investigação em documentos escritos, visto que estes são "[...] insubstituível em qualquer reconstituição" Cellard (2008, p. 295) sinaliza a importância dos documentos escritos em pesquisa das ciências sociais, afirmando ser referente a um passado relativamente distante, pois, não é raro que ele represente quase a totalidade dos vestígios da atividade humana, em determinadas épocas, também o autor diz que a memória pode modificar ou deformar os acontecimentos ao longo do tempo e com isso, os documentos tornam-se muito frequentementes "[...] o único testemunho de atividades particulares ocorridas em um passado recente" (CELLARD, 2008, p. 296).

Dentre a vasta gama de documentos escritos, optou-se por usar os manuais pedagógicos. E, visto sua notoriedade neste artigo, sente-se necessidade de defini-los. Uma forma de definição é de que são livros didáticos destinados ao uso do professor, seja em sua formação para posterior atuação docente ou exatamente na sua atuação como professor. Enquanto o livro didático apresenta proposições de exercícios e problemas aos alunos, o manual pedagógico abrange aspectos pedagógicos e metodológicos do ensino.

Valente (2008, p. 12) aponta que "Os livros didáticos constituem-se em elementos fundamentais para a pesquisa do trajeto histórico da educação matemática". Livro didático e educação matemática parecem elementos indissociáveis.

A análise de livros didáticos permite, ainda, que se compreenda o momento histórico em que foram publicados, aquilo que Cellard (2008, p. 299) denomina de contexto e defende ser primordial se inserir para compreender a "[...] conjuntura política, econômica, social, cultural que propiciou a produção de um documento[...] além da importância dessa

\footnotetext{
${ }^{8}$ No próximo tópico este conceito será debatido.
} 
imersão para evitar que a interpretação do conteúdo seja realizada em função de valores modernos" (CELLARD, 2008, p. 300).

Choppin $(2009$, p. 9) expõe que "Depois de trinta anos, a questão da definição do manual escolar é relevada de maneira recorrente pelos historiadores da educação", ainda que "[...] os livros escolares são, há muito tempo, apresentados aos seus contemporâneos sob uma multiplicidade de denominações" (p. 15).

Apesar de utilizar, recorrentemente, livros didáticos e manuais pedagógicos como sinônimos, destaca-se que, como já explicitado, os primeiros correspondem a obras destinadas aos alunos, com exercícios, problemas propostos, enquanto os manuais pedagógicos são livros utilizados pelo professor, com aspectos pedagógicos e metodológicos do ensino. Sendo que, nesta pesquisa, analisar-se-ão os chamados manuais pedagógicos, que de acordo com Silva:

[...] são assim denominados por terem sido escritos a fim de desenvolverem os temas previstos para 0 ensino de disciplinas profissionalizantes dos currículos de instituições de formação docente, no caso, aquelas diretamente relacionadas com questões educacionais, a saber, a pedagogia, a didática, a metodologia e a prática de ensino (SILVA, 2003, p. 30). 
Schubring (2003, p. 59) afirma que esses documentos "Tradicionalmente, foram tratados mais ou menos com desdém, sendo considerados desinteressantes ou até mesmo entediantes". Porém, ocorreram mudanças e cresceu o interesse nas últimas décadas em pesquisar aspectos sobre os livros escolares. Choppin (2002) justifica que tal interesse, historicamente, 'tardio' não o surpreende, visto que, são diversos os fatores responsáveis por motivar tal desinteresse, dentre os motivos "[...] eles não apresentam nada de raro, exótico, singular; parecem mesmo intemporais, na medida em que transcendem a clivagem entre as gerações" (p. 6). Outro fator a se considerar é que são mercadorias perecíveis e "Perdem todo valor de mercado assim que uma mudança nos métodos ou nos programas fixam sua prescrição, ou ainda, quando fatos atuais impõemIhes modificações" (p. 6-7), nesse mesmo sentido, os livros/manuais "[...] são também vítimas de seu sucesso" (p. 7).

Choppin (2002) ainda relata que o interesse em pesquisas históricas, que os tenham como fonte, surgiu nos anos de 1970, quando iniciou-se o entendimento das possíveis contribuições desses documentos. Tal interesse se deu pela compreensão de que esse tipo de documento "[...] constitui um testemunho escrito, portanto permanente, infinitamente mais elaborado, mais detalhado, mais rico que as instruções que supõe preparar" (CHOPPIN, 2002, p 14). Valente (2008, p.141) corrobora afirmando que o livro didático "[...] até pouco tempo atrás era considerado uma literatura completamente descartável, de segunda mão", mas "[...] tornaram-se preciosos documentos para a escrita da história dos saberes escolares".

O objeto de investigação nos manuais pedagógicos foram os jogos para o ensino de aritmética9. O jogo é uma forma de tornar o ensino de matemática mais interessante e ainda um meio de aproximar os conteúdos da realidade do aluno. Moura (1999, p. 86) indica que "A matemática deve

9 Enfatiza-se que se optou pela nomenclatura de 'jogos para 0 ensino de matemática/aritmética' ao invés de jogos de matemática/aritmética, com vistas que não há jogos de matemática/aritmética, há jogos que podem ser aplicados no ensino de matemática/aritmética. 
buscar no jogo (com sentido amplo) a ludicidade das soluções construídas para as situações-problema seriamente vividas pelo homem", unindo assim, o prazer proporcionado pelos jogos com situações cotidianas. Além de apontar que "[...] na educação matemática [há] uma certa tendência para uso do jogo" (MOURA, 1999, 81).

Smole, Diniz e Cândido reforçam essa ideia:

Todo jogo por natureza desafia, encanta, traz movimento, barulho e uma certa alegria para o espaço no qual normalmente entram apenas o livro, o caderno e o lápis. Essa dimensão não pode ser perdida apenas porque os jogos envolvem conceitos de matemática. Ao contrário, ela é determinante para que os alunos sintam-se chamados a participar das atividades com interesse (SMOLE; DINIZ; CÂNDIDO, 2000, p. 10).

Ao inserir os jogos nas aulas de matemática, é necessário partir da concepção de que o professor é o mediador do conhecimento e que possui intencionalidade em todas as situações propostas. Da mesma forma, este professor pressupõe alunos como construtores de seu próprio conhecimento, que questionem e aprendam em interação com seus pares (ELORZA, 2013, p. 44).

Um jogo para se tornar pedagógico, precisa apresentar uma intenção pedagógica e no caso da matemática, Mattos indica que:

[...] deve proporcionar ao educando informações sobre a linguagem matemática e estar relacionado ou co-relacionado com um conteúdo matemático. Durante o jogo, ocorre uma transformação de comportamento na criança, pois, mesmo jogando com outras crianças, começa a fazer um diálogo consigo mesma, pois as outras são adversárias naquele momento. Assim, as reações e atitudes provocadas pelo jogo estimulam estratégias diversas (MATTOS, 2009, p. 72).

Ao realizar busca por trabalhos que tratassem da mesma temática, encontrou-se um artigo de autoria de Costa (2015b) que trata de Theobaldo Miranda Santos e um dos seus manuais, porém Costa (2015b) tinha objetivos alheios aos desta pesquisa. Neste sentido, aponta-se que não foi encontrado nenhum trabalho que tivesse interesse de verificar o papel dos jogos para o ensino de aritmética nos manuais pedagógicos de autoria de Theobaldo Miranda Santos, o que evidencia a relevância desta pesquisa no campo da 
História da educação matemática e da Educação Matemática de forma geral.

Para finalizar este tópico, aponta-se que o presente artigo tem por objetivo compreender o papel dos jogos, para o ensino de aritmética em três manuais pedagógicos de autoria de Theobaldo Miranda Santos.

\section{THEOBALDO MIRANDA SANTOS}

Theobaldo Miranda Santos é o autor dos manuais pedagógicos que serão analisados a seguir.

Santos nasceu em 1904, na cidade de Campos- RJ. Iniciou seus estudos no Liceu de Humanidades e na Escola Normal Oficial (curso primário e secundário) e concluiu em 1920. Também cursou Odontologia e Farmácia no Colégio Metodista Grambery, em Juiz de Fora. Logo após, iniciou o magistério na Escola Normal de Manhuaçu, Minas Gerais. Ao retornar a Campos, em 1928, ministrou aulas de Física, Química e História Natural no Liceu de Humanidades. Ainda lecionou História da Civilização, no Colégio Nossa Senhora Auxiliadora. Não bastasse tudo isso, em Campos, tornou-se catedrático na Escola Superior de Agricultura e Veterinária, ministrando aulas de História Natural (ALMEIDA FILHO, 2008).

Foi a partir de 1932 que seus primeiros artigos relacionados a questões educacionais começaram a ser publicados em jornais e revistas de Campos, Niterói e Rio de Janeiro. Ainda em Campos, foi professor de Ortodontia e Odontopediatria, na Faculdade de Farmácia e Odontologia. Em 1938, transferiu-se para Niterói, onde lecionou História Natural no Instituto de Educação. Nesse mesmo período foi nomeado professor da antiga Universidade do Distrito Federal, onde ocupou a cátedra de Prática de Ensino. Santos exerceu, ainda, funções como professor do curso de Pedagogia, na Escola do Serviço Social e de Física no Colégio Sion do Rio de Janeiro na década de 1940 (ALMEIDA FILHO, 2008) 
Figura 1: Theobaldo Miranda Santos

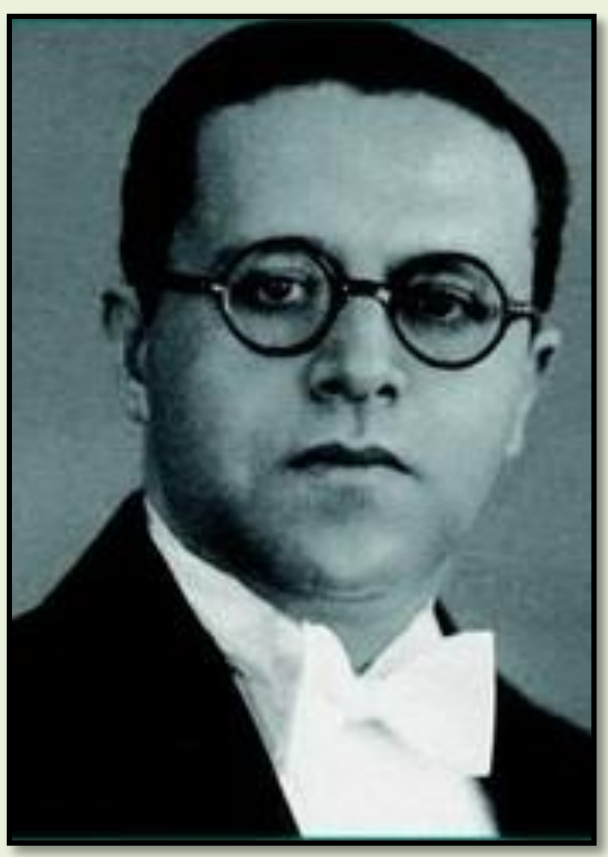

Fonte: Silva (2014).

Em 1941 recebeu a nomeação de Diretor de Departamento de Educação Técnico Profissional e, no ano seguinte, ocupou o cargo de diretor

Geral do Departamento de Educação Primária da prefeitura do Rio de Janeiro. Ao mesmo tempo, era professor na Pontifícia Universidade Católica do Rio de Janeiro. Em 1944, recebeu a nomeação de Cátedra de Filosofia da Educação do Instituto de Educação do Rio de Janeiro. Ainda no Instituto de Educação, exerceu, por duas vezes, as funções interinas de Secretário Geral de Educação e Cultura da prefeitura do antigo Distrito Federal, bem como, ocupou também o cargo de Diretor do Departamento de Difusão Cultural na mesma cidade, por duas vezes. Santos aposentou-se aos 53 anos, momento em que começou a se dedicar, com exclusividade, na produção de livros, o que fez até seu falecimento aos 66 anos, em 1971 (ALMEIDA FILHO, 2008). Além disso:

Os primeiros livros voltados para a formação de professores publicados por Santos foram os livros: A criança, o sonho e os Contos de Fada pela editora S.E. Panorama Ltda, em São Paulo, no ano de 1941 e Filosofia da Educação pela Editora Boffoni, sediada no Rio de Janeiro, em 1942, livro este que foi reedidado pela Companhia Editora Nacional nas coleções Atualidades Pedagógicas e Iniciação 
Científica com o título Manual de Filosofia (ALMEIDA FILHO, 2009, p. 78).

Zimmer, Boldo e Costa complementam que:

Por aproximadamente três décadas, seus volumes publicados circularam em outros meios estudantis dos cursos das Escolas Normais, Institutos de Educação e Faculdades de Filosofia, Ciências e Letras. Ele publicou também livros didáticos de geografia, história, língua portuguesa, contos e poesias para o ensino primário, ginasial e colegial. Dessa forma, o referido autor construiu uma ampla literatura que abrangeu os três níveis de ensino: o primário, o secundário, o ensino normal e superior e, sobretudo, as Faculdades de Pedagogia (ZIMMER, BOLDO; COSTA, 2013, p. 3).

Santos tinha seus ideais alinhados aos do grupo dos 'católicos', que possuíam um projeto de conformação do campo educacional, como estratégia de intervenção na cultura, ligados ao Centro D. Vital, fundado em 1921. Santos "[...] tornou-se um autor militante que produziu uma vasta literatura no campo da Ciência de Educação" (ALMEIDA FILHO, 2008, p. 2). Nas três primeiras décadas do século XX, os católicos lutavam pela 'aula de religião' nas escolas, porém esse discurso, após o período citado acima deixou de ser a questão central do grupo, sendo que a grande preocupação dos católicos passou a ser a construção de:

[...] um projeto estratégico de intervenção na cultura pela formação do professor que possuía uma ação direta na escola. Não bastava conquistar uma aula de religião no currículo, caso não fosse construído um modelo pedagógico católico (ALMEIDA FILHO, 2008, p. 3).

Almeida Filho (2008) afirma que as obras de Theobaldo Miranda Santos representam o esforço na adequação das concepções escolanovistas a um modelo de pedagogia dos católicos, permitindo a compreensão das estratégias católicas na formação de professores e na educação de forma geral. E foi através da produção e circulação de materiais pedagógicos como manuais que essas ideias e concepções passariam a circular.

Com a existência de dois grupos, católicos e escolanovistas, que desejavam a construção de modelos educacionais com princípios distintos, 
as obras de Santos, pertencendo ao grupo dos católicos, a partir do ano de 1945 começaram a disputar espaços com livros escolanovistas, sistematizaram o campo das ciências educacionais, "[...] construindo modelos de saberes escolares na perspectiva da pedagogia católica. Nesse sentido, as coleções eram modelares, pois organizavam o campo educacional, conformando a cultura escolar" (ALMEIDA FILHO, 2008, p.4).

\section{AS EDITORAS}

Costa (2015a), a partir de seus estudos diz que o livro/manual realmente não é fruto de escolhas somente do autor, mas também, da editora. Sendo que entre estes, há uma tensa relação, visto que, o texto que o autor apresenta ao editor é "[...] aquele com sua melhor forma de concepção, enquanto que, para o editor, o melhor texto é aquele que consegue obter bons lucros. Nessa relação sensivelmente desequilibrada, a palavra final é dada pelo editor" (p. 69-70).

Nesse sentido, pontuam-se, a seguir, detalhes sobre a editora, responsável pela publicação dos três manuais: Companhia Editora Nacional (CEN).

A CEN foi uma importante editora no que diz respeito à disputa entre os defensores da Escola Nova e os católicos, que possuía "[...] dupla estratégia: produzir livros para o mercado de trabalho e construir um modelo de leitura católica educacional" (ALMEIDA FILHO, 2008, p. 1). Apesar de a CEN buscar construir esse modelo de leitura católica, foi a própria editora que em junho de 1932 publicou o Manifesto dos Pioneiros da Escola Nova.

A CEN surgiu após a crise da Companhia Gráphico de propriedade de Monteiro Lobato, em 1925. [...] com a falência da Editora Monteiro Lobato e Cia, nasceu a CEN que foi montada com o ex contador de Monteiro Lobato, Octalles Marcondes Ferreira, agora seu sócio no novo empreendimento editorial. [...] Desde a sua fundação, em 1925, a CEN teve na produção de livros voltados para o ensino uma estratégia comercial que passava pela publicação de impressos educacionais do ensino primário ao superior. Sua estratégia visava conquistar um público leitor ligado à educação (ALMEIDA FILHO, 2008, p. 25). 
"Desde seu primeiro ano de existência, a Nacional dividiu sua produção em livros escolares, de literatura e poesia" (TOLEDO, 2004, p. 3). Sendo assim, os livros didáticos sempre estiveram entre os primeiros da lista de publicações da CEN. Devido ao sucesso com a publicação de livros didáticos, a CEN passou a publicar livros das mais variadas áreas de conhecimento, inclusive para a formação de professores:

\begin{abstract}
Estes livros são voltados para a formação de futuros professores e possíveis consultas de educadores já formados e/ou que atuavam no magistério como professores e não tiveram formação pedagógica (sobretudo no interior do país e no meio rural, onde atuavam muitos professores sem a formação específica para o magistério. Santos ${ }^{10}$ tornou-se um autor que poderia estar em todo contexto da vida do professor: em sala de aula como professor ou em sala de aula como aluno (ALMEIDA FILHO, 2008, p. 35).
\end{abstract}

Hallewell (1985, p. 254) afirma que a CEN "[...] ocupou o primeiro lugar entre as firmas brasileiras, dedicadas exclusivamente à edição de livros, desde 1921, até princípios da década de 1970, sem interrupções". Em seu período de ascensão, tornou-se responsável pela publicação de mais de $30 \%$ dos livros brasileiros.

\title{
OS MANUAIS PEDAGÓGICOS DE AUTORIA DE SANTOS
}

\section{Noções de didática especial}

Este manual é datado de 1960 e foi publicado pela Companhia Editora Nacional e é o sétimo volume de um total de quinze da coleção 'Curso de psicologia e pedagogia'. 
Figura 2: Capa do manual 'Noções de didática especial'

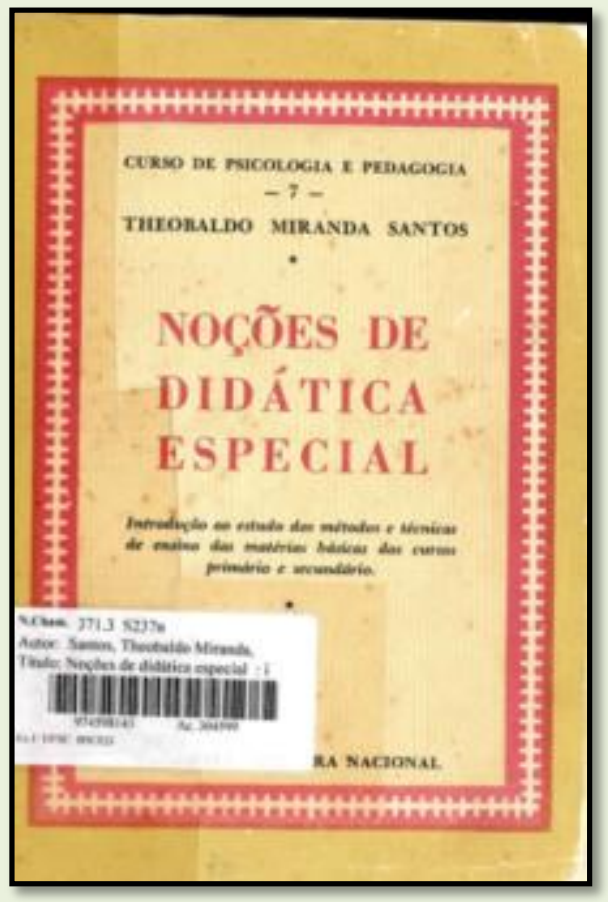

Fonte: Santos (1960).

O manual não trata exclusivamente de aritmética. Ele possui indicações de didática de Geografia, História, Ciências Naturais, Matemática e Língua Portuguesa, sendo que cada disciplina tem um capítulo correspondente.

No prefácio, Santos $(1960$, p. 7) indica que esse manual é simples e elementar e possui o único propósito de "[...] auxiliar os jovens estudantes que, nas escolas normais e faculdades de filosofia, se preparam para a mais difícil de tôdas as tarefas - a de educar as novas gerações".

Sobre o ensino de aritmética, Santos (1960) preocupa-se em citar importantes nomes como Goethe, Pascal, Hamilton, Nietzsche. Interessante que, apesar de, como já visto, Theobaldo pertencer ao grupo dos católicos, faz menções a nomes como Claparède e Thorndike, importantes figuras do escolanovismo. Thorndike é citado, novamente, quando Santos refere-se aos objetivos do ensino de matemática.

Além do tópico geral sobre a didática da matemática, há dois capítulos específicos para a escola primária e secundária, respectivamente. Sobre a escola primária destaca-se que um dos seus objetivos é "[...] 
proporcionar à criança o conhecimento dos números em busca da solução de problemas práticos na existência humana" (SANTOS, 1960, p. 143), justificando que o ensino de matemática, deve, desta forma, "[...] ser ministrado com aproveitamento de situações reais da vida" (p. 144).

É no tópico 'Prática de ensino de aritmética' que os jogos são citados. Santos baseia-se nos programas mínimos do ensino primário, organizados pela Secretaria Geral de Educação e Cultura do Distrito Federal para estabelecer as normas didáticas para a aprendizagem de aritmética. Das recomendações gerais, destaca-se que "Aproveitar, sempre, como motivação de ensino, as situações reais da vida relacionando-as com as necessidades e interêsses das crianças" (p. 150). Como complemento a essa recomendação geral, há recomendações sobre treino nos exercícios e jogos, em que os jogos são tratados como uma forma de exercício de treino. Todas as recomendações versam sobre a forma como os exercícios devem ser: curtos, repetidos, variados, expor poucos conhecimentos de cada vez, não se deve desperdiçar tempo e energia com treino de valor prático insignificante, exigência de exatidão, diferente nível de dificuldade para alunos de diferentes níveis de capacidade. Logo, a palavra Jogo foi inserida nessas recomendações como sinônimo de exercícios.

Os jogos são citados, novamente, no tópico relacionado à 'motivação do ensino de aritmética':

\footnotetext{
O professor deve fazer tudo para tornar o ensino de aritmética interessante e agradável. Para isso, é preciso relacioná-lo com a experiência, o interêsse e as situações reais da vida da criança, transformando sua aprendizagem numa atividade espontânea e criadora. O emprego de jogos, de projetos, de centro de interêsse, de instituições escolares, como o banco, a feira a loja e de certas atividades educativas, como a jardinagem, o trabalho manual e a economia doméstica muito concorrem para tornar a aprendizagem da aritmética atraente e divertida (SANTOS, 1960, p. 152, grifos nossos).
}

Sob essa ótica, constata-se que para Santos os jogos são meios de motivar os alunos no ensino de aritmética. Ao tratar do material de ensino de aritmética, Santos (1960) diz que quando a criança chega à escola ela tem 
dificuldade de abstração e o uso de materiais concretos, facilita a aprendizagem de operações aritméticas, exemplificando que tal material, pode ser, desde os próprios dedos da mão, pedrinhas, feijões, até ábacos, tabuleiros, coleções de pesos e medidas, relógio escolar e inclusive os jogos aritméticos. Ou seja, sugere-se que os jogos sejam utilizados como forma de concretizar os números e ir familiarizando as crianças com a abstração presente no ensino de aritmética.

Apesar de o autor ser redundante em frisar a necessidade do uso dos materiais, ele alerta para que estes só sejam utilizados no início do ensino, para a criança "[...] aprender a pensar independente dos objetos" (p. 153), evidenciando que para santos os jogos e materiais concretos são necessários apenas para o ensino de aritmética para crianças em nível inicial de escolaridade.

Após tratar da matemática na escola primária, Santos dedica um capítulo para tratar do seu ensino na escola secundária, sendo que nessa fase, o ensino de matemática tem como objetivo que o aluno domine a aritmética de modo a compreender a natureza e o uso dos números em situações cotidianas.

Os jogos são timidamente citados nesse tópico. Apesar de Santos destacar no quadro sinótico as técnicas de ensino, segundo professor José Elídio Pérez Somossa, os jogos são citados como processos ativos, para o ensino de aritmética. Santos (1960, p. 167) indica que, "[...]o método dos jogos não pode ser empregado com exclusividade na escola secundária; é uma técnica mais adequada aos objetivos e à mentalidade dos alunos da escola primária e do jardim de infância".

Por fim, sintetiza-se que Santos teve formação acadêmica bem variada, sendo que seu interesse pela pedagogia parece ter florescido ao se tornar professor de pedagogia em 1940, além disso, ele pertencia ao grupo dos católicos, que objetivavam além da inserção da aula de religião nas escolas, a construção de um modelo pedagógico católico.

Sobre o manual analisado, destaca-se que é um exemplar que contempla indicações didáticas de cinco disciplinas, dentre elas, a de 
Matemática. Sendo que, em dois dos tópicos do capítulo, relacionado à Matemática, Santos fala dos jogos, enfatizando que devem ser aproveitadas como motivações às situações reais, interesses das crianças e que são uma forma de concretizar os números. Nessa obra de Santos (1960), verificou-se uma abordagem diferenciada, pois ele não sugere jogos, explicitando como aplicá-los, apenas os cita, pontualmente, como forma de motivação ou como um material de ensino da matemática. Os jogos são indicados, de forma mais recorrente no ensino primário e infantil, apesar de que mesmo nestes níveis é indicado que, aos poucos, sejam retirados do processo de ensino, para que ocorra a abstração dos conceitos de matemática. De forma geral, é nítida a exposição do uso dos jogos para o ensino de aritmética como meio de aproximar o ensino de preceitos da psicologia da educação e desta forma propiciar um aprendizado mais significativo, ao passo que o torna mais dinâmico e divertido.

\section{Metodologia do ensino primário}

O exemplar tomado para análise é datado de 1952, publicado pela Companhia Editora Nacional, trata-se da $3^{a}$ edição e o décimo volume da coleção 'Curso de Psicologia e Pedagogia'. Essa coleção é composta por 21 manuais, todos de autoria de Theobaldo Miranda Santos e possui variadas temáticas, dentre elas filosofia, História, Psicologia, Sociologia, Biologia, Administração Escolar, Práticas de Ensino, Noções de Didática Geral e Especiall1, Metodologias, Manuais do professor primário ${ }^{12}$ e secundário, dentre outros. Vislumbra-se, assim, a vasta produção de Theobaldo Miranda Santos no campo educacional. 
Figura 3: Capa do manual 'Metodologia do Ensino Primário'

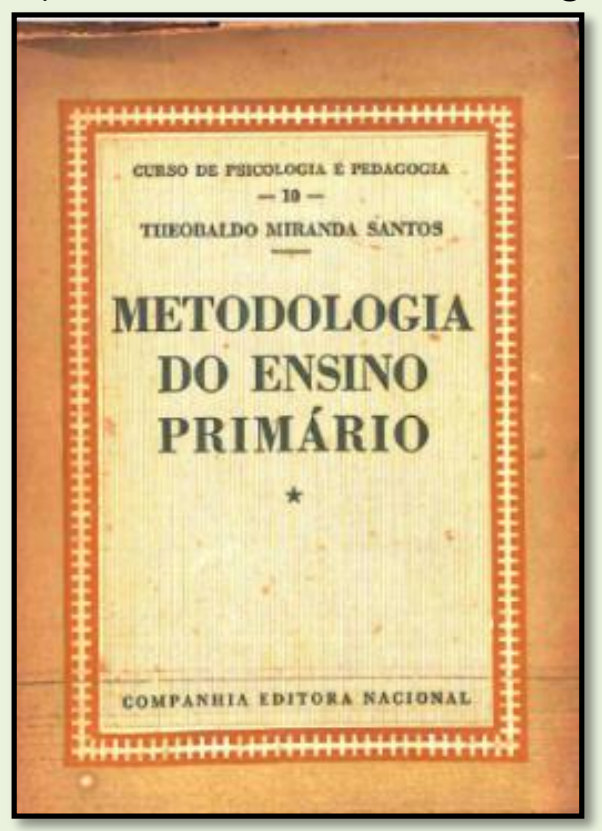

Fonte: Santos (1952).

Todos os manuais ${ }^{13}$ de Theobaldo possuem a característica de não tratarem especificamente de uma disciplina, costumeiramente, ele trata de aspectos gerais da educação e após, faz especificações de acordo com seus conteúdos. Em todos, ele defende que o ensino deve ter motivações propiciadas por uma aula viva, agradável, atraente, que considere os interesses e a vida do aluno.

Nas primeiras páginas do manual há a indicação "De acordo com os programas dos Institutos de Educação e das Escolas Normais" (SANTOS, 1952, p. 3), dando um indicativo de seu uso nestes estabelecimentos de ensino.

Santos foi um autor, educador e estudioso pertencente ao grupo dos católicos, isso é nítido em um capítulo exclusivo sobre 'Métodos ativos e Escolas novas' em seu manual, em que ele expõe o que foi a escola nova e suas características, o que são os métodos ativos, bem como, cita alguns

13 Analisados nesta pesquisa.

Revista Exitus, Santarém/PA, Vol. 9, N² 2, p. 76 - 104, ABR/JUN 2019. 
métodos como o de Montessori, de Dalton, de projetos, de centros de interesse, Cousinet, Jena, Winnetka. Santos os descreve, ressalta as positividades de seu uso, mas reserva as últimas linhas a críticas e apontamentos de inconvenientes sobre estes métodos, reforçando seu posicionamento como católico. Santos posiciona-se a favor do ajustamento do método conforme a natureza psicológica do aluno e características do professor, pois "[...] por mais científico e perfeito que seja o método, êle de nada valerá sem a inteligência criadora, o amor devotado e o exemplo vivo do professor" (SANTOS, 1952, p. 101).

Como exposto acima, o manual possui duas partes, a primeira destinada à metodologia geral e a segunda à metodologia especial. Em ambas as partes, há grande preocupação do autor em indicar aspectos históricos referentes ao tema central do tópico, como por exemplo, salienta a história da palavra método'14, lição ${ }^{15}$, aponta os métodos primitivos, a história do ensino de cada matéria abordada no manual, etc.

A primeira menção à palavra jogo encontra-se na página 69, quando Santos refere-se a material didático. O autor expõe muito mais sobre materiais do que os jogos em si.

O jogo aparece nas considerações teóricas referentes à importância básica no processo de ensino e aprendizagem, citando Comênio, Pestalozzi e Froebel como precursores. Nesse ponto, não se sabe se Santos defende ou não o uso de jogos, pois, o que ele faz no manual é apontar aspectos históricos e teorias. Nesse mesmo capítulo, indica os tipos de materiais didáticos e o jogo é citado como um material de trabalho que "são empregados por diversos sistemas de educação renovada, como o material de Froebel, de Montessori, de Decroly de Agazi, o Discat, o Abbat" (SANTOS, 1952, p. 71). Percebe-se, novamente, imparcialidade do autor ao se referir ao jogo. Trata-se de uma exposição de teorias e de outros autores que defendem e/ou produzem os jogos.

14 De origem grega e significa "caminho para chegar a um fim" (SANTOS, 1952, p. 15).

15 Segundo a etimologia da palavra lição (de lectio) significa leitura (SANTOS, 1952, p.74). 
No capítulo destinado à metodologia da aritmética, inicialmente, o autor apresenta um pouco da história do ensino de aritmética ${ }^{16}$, fala de técnicas de ensino e é no tópico Práticas de ensino de aritmética que Santos indica "Recomendações sôbre o treino nos exercícios e jogos". São 11 recomendações no total, que dissertam sobre a importância da compreensão preceder o treino, da importância de insistir em questões que a criança tem dificuldade, de não desperdiçar tempo e da exatidão que deve preceder a rapidez. As recomendações versam muito mais sobre exercícios do que jogos, presumindo-se assim, que para Santos os jogos são formas de exercício, treino e fixação de conteúdos ou ainda, que para ele jogos e exercícios são termos sinônimos.

No tópico referente à motivação no ensino de aritmética, percebe-se outra visão de Santos, a relevância de relacionar a aritmética a experiência, interesse e situações reais da vida da criança. Os jogos são citados e equiparados ao uso de projetos, centros de interesse como meios de tornar a aprendizagem de aritmética atraente, divertida, mais fácil e mais viva. Nesse contexto, o autor cita atividades educativas como jardinagem, trabalho manual e a economia doméstica como meios de proporcionar a motivação nos alunos. Verifica-se, novamente, que Santos não apresenta clareza sobre o que é um jogo, inclusive o assemelha-o a outras atividades.

Em outro momento, os jogos são indicados como material de ensino de aritmética. Apenas no final do capítulo sobre a metodologia da aritmética é que são citados alguns jogos. Santos cita Backheuser ${ }^{17}$ que sugere o uso de material preparado pelos alunos ou pelo professor e dentre estes materiais estão os jogos de damas, dados, dominó, jôgo da glória, dinheiro de brinquedo, bandeirinhas, folhinhas, calendário, etc. Apesar de citar, em nenhum momento, Santos apresenta um dossiê ou instruções do jogo.

16 Apresenta o início da aritmética desde a antiguidade oriental, cronologia dos reis e dinastias, medição de terras... (SANTOS, 1952).

${ }^{17}$ BACKHEUSER, Everardo. Como se ensina aritmética. Rio de Janeiro, Pôrto Alegre, São Paulo: Livraria do Globo, 1946. 
O manual 'Metodologia do ensino primário' bem como outros de autoria de Santos, difere-se, em sua estrutura. Primeiro, por não ser um manual exclusivamente destinado à aritmética e, segundo, porque no único momento que ele citou alguns jogos, estes, ainda, foram parafraseando outro autor. Santos preocupou-se em trazer aspectos históricos, teóricos, críticas a métodos, devido a isso o percentual de jogos em seu manual é pequeno. $E$, ainda quando os cita, apresenta uma erudição confusa, pois, por vezes, trata os jogos como sinônimo de exercícios de fixação, outras vezes os assemelha a projetos e centros de interesse. A única opinião de Santos, que converge ao longo de todo o manual, é a de que o jogo é uma forma de tornar o ensino de aritmética mais interessante, divertido e vivo para o aluno. E este papel atribuído ao jogo está em consonância com os pressupostos escolanovistas, especialmente no que diz respeito à psicologia, de modo a aproximar as atividades escolares à vida das crianças e consequentemente propiciar um ensino divertido e interessante.

\section{Manual do professor primário}

A terceira obra de Theobaldo Miranda Santos a ser analisada, denomina-se 'Manual do Professor Primário', publicado pela Companhia Editora Nacional, datado de 1960. Trata-se da análise de um exemplar da $5^{a}$ edição deste manual. Como exposto na análise anterior, este manual também faz parte da coleção 'Curso de Psicologia e Pedagogia'. 
Figura 4: Capa do 'Manual do Professor Primário'

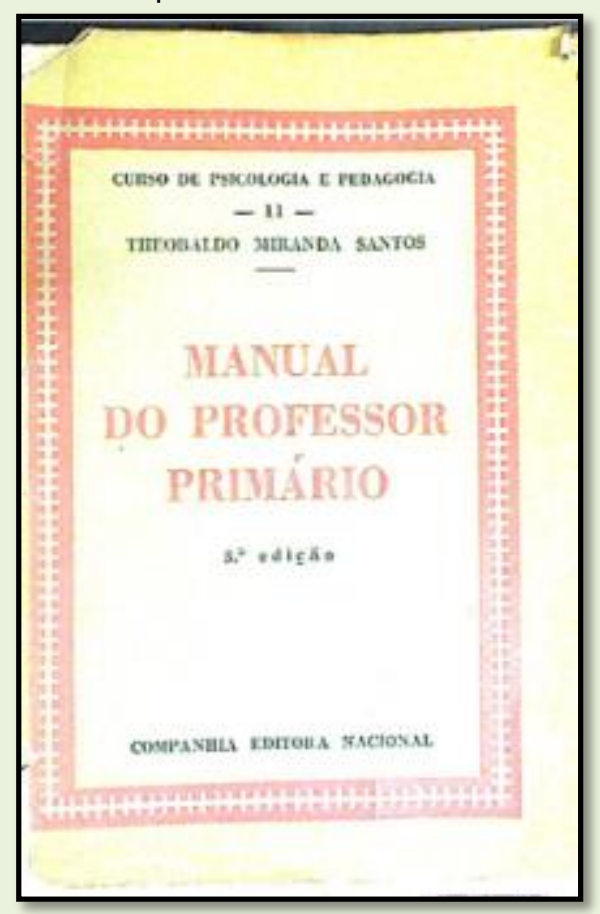

Fonte: Santos (1960).

Ao iniciar a análise deste manual, percebeu-se que os conteúdos, tópicos são os mesmos ao manual anterior 'Metodologia do ensino primário'. Do prefácio até a última página, não há diferença entre um e outro manual. O curioso é que ambos fazem parte da mesma coleção, como indicado no próprio manual:

Figura 5: Exemplares da coleção 'Curso de Psicologia e Pedagogia' 


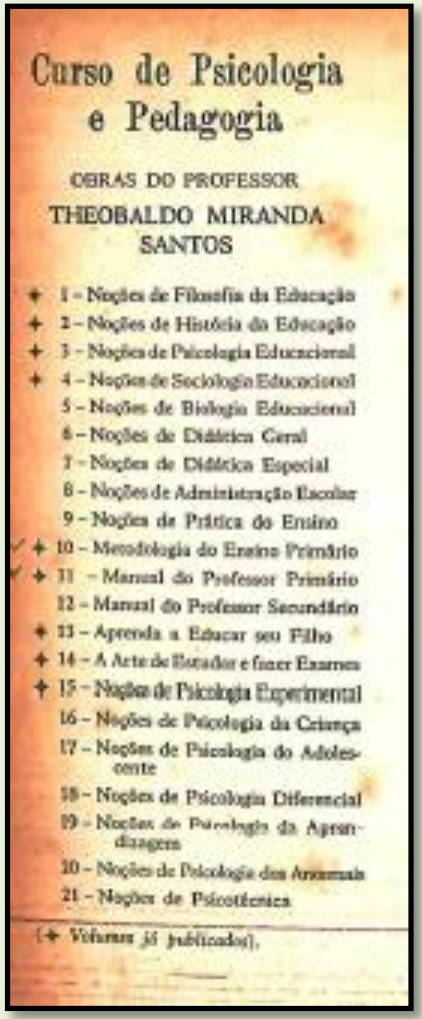

Fonte: Santos (1952).

Todo o conteúdo, na íntegra, é o mesmo do manual anterior, assim, afirma-se que as indicações do uso de jogos também são as mesmas e nos mesmos tópicos. Dessa forma, infere-se que, sendo este manual de 1960 e o anterior de 1952, que o autor, ao longo de sua produção, sentiu a necessidade de alterar o título de sua obra.

\section{CONSIDERAÇÕES FINAIS}

Realizar pesquisas na história da educação matemática, que tenham os manuais pedagógicos como fontes de pesquisa, permite a construção de uma representação do que acontecia em outros tempos. Neste sentido, o objetivo deste artigo foi compreender qual o papel dos jogos para o ensino de aritmética, em três manuais pedagógicos de autoria de Theobaldo Miranda, editados em 1952 e 1960.

Theobaldo Miranda Santos foi um autor destacado, visto sua formação diversificada, bem como, seu posicionamento como pertencente ao grupo 
dos católicos. Apesar disso, suas obras mostraram ser tentativas de adequação dos preceitos escolanistas, aos pressupostos católicos.

Os três manuais analisados foram publicados pela Editora Companhia Nacional e, caracterizam-se por não serem exclusivamente de aritmética, mas mesclam diferentes matérias de ensino.

No primeiro manual, 'Noções de didática especial', Santos (1960) é enfático em apontar a necessidade de aproveitar situações cotidianas para aguçar o interesse das crianças. Quando cita jogos, defende com formas de exercícios de treino, recomendando, inclusive, que os mesmos não deveriam desperdiçar tempo. Por vezes, os jogos estão atrelados à ideia de motivação e como meio de concretizar os números e ir familiarizando as crianças com a abstração. Em nenhum momento, Santos (1960) indica um jogo em específico, apenas cita suas potencialidades.

No manual Metodologia do Ensino Primário, de 1952, Santos (1952) apresenta um posicionamento um tanto quanto confuso em relação aos jogos, pois, por vezes, os jogos são tratados como exercícios de fixação, em outros momentos aproximam-se a projetos e centros de interesse. Porém, uma ideia é convergente ao longo de todo o manual: o jogo é um meio de tornar o ensino de aritmética mais interessante, divertido e vivo para o aluno. Assim como nos outros manuais de sua autoria, Santos não citou jogos, ou indicou algum em específico.

O terceiro e último manual analisado foi 'Manual do Professor Primário', de 1960. Percebeu-se que este e o manual citado anteriormente possuem, integralmente, o mesmo conteúdo.

Apesar dos manuais de Theobaldo não serem exemplares que se preocupam, exclusivamente, em expor exemplos e passo a passo de jogos, o autor deixa claro que seu posicionamento é a favor de jogos que possam contribuir para um ensino de aritmética, mais significativo, divertido e interessante ao aluno. Desta forma, os manuais se tornam um subsídio para a reflexão e planejamento do professor, e não um 'guia' a ser seguido como única ferramenta. Infere-se que as motivações do autor para citar e defender o uso de jogos como forma de aproximar o aluno dos conceitos de 
aritmética, seja proveniente do cenário do momento, a qual estavam em voga as discussões acerca da Escola Nova, que por sua vez, tinha como prerrogativa, o aluno ser o centro do processo de ensino e aprendizagem e desta forma o ensino seria configurado, trazendo a tona discussões sobre centro de interesses, métodos de projetos e também o uso de jogos.

Com isso, conclui-se que Santos apontava os jogos como meios de tornar a aritmética divertida, interessante, próxima ao cotidiano dos alunos, apesar de apresentar erudição turva ao definir, propriamente, seu posicionamento quanto ao papel dos jogos. Talvez esta confusão tenha se dado pelo fato destes manuais (e tantos outros escritos por ele) serem tentativas de adequação de sua postura católica, frente a ideias liberais dos escolanovistas.

A partir da pesquisa que foi descrita neste artigo, suscitam novas inquietações, que porventura, serão propulsoras de novos estudos e publicações, como por exemplo, o caso dos manuais 'Metodologia do Ensino Primário' e 'Manual do Professor Primário' que possuem integralmente os mesmos conteúdos. Foram realizadas algumas inferências sobre isso, mas aprofundamentos referentes a isso podem indicar fatos que justifiquem este caso, motivando novos estudos.

\title{
REFERÊNCIAS BIBLIOGRÁFICAS
}

\begin{abstract}
ALMEIDA FILHO, O. J. A estratégia da produção e circulação católica do projeto editorial das coleções de Theobaldo Miranda Santos: (1945 - 1971). 2008, 368 f. Tese (Doutorado - Educação: História Política Sociedade) Pontifícia Universidade Católica de São Paulo. São Paulo, 2008.
\end{abstract}

CELLARD, A. A análise documental. In: POUPART, Jean. A Pesquisa Qualitativa: enfoques epistemológicos e metodológicos. Petrópolis: Vozes, 2008, p. 295-316.

CERTEAU, M. de. A escrita da história. 3. ed. Rio de Janeiro: Forense Universitária, 2013. Tradução de: Maria de Lourdes Menezes.

CHARTIER, R. A história ou a leitura do tempo. Belo Horizonte: Autêntica, 2010. 
CHOPPIN, A. O historiador e o livro escolar. História da Educação. Pelotas. n. 11, abr. 2002. p. 5-24.

CHOPPIN, A. O manual escolar: uma falsa evidência histórica. Trduação de Maria Helena Bastos. Revista História da Educação, Pelotas, v. 13, n. 27, p. 0975, 2009.

COSTA, D. A. Livros e textos didáticos como fonte para as pesquisas de história da educação matemática. In: Grupo de Estudos em Educação Matemática: ações cooperativas e colaborativas por várias vezes. São Carlos: Pedro \& João Editores, 2015a.

Costa D. A. Theobaldo Miranda Santos and the Methodology of Teaching Artithmetic. RIPEM - International Journal for Reserarch in Mathematics Education, v.5, n.4, p. 105-116, 2015b.

COSTA, D. A; VALENTE, W. R. O repositório de conteúdo digital nas pesquisas de história da educação matemática. Rev. Iberoam. Patrim. HistóricoEducativo, Campinas (SP), v. 1, n. 1, P. 96-110, jul./dez. 2015.

ELORZA, N. S. L. O uso de jogos no ensino e aprendizagem de Matemática nos anos iniciais do Ensino Fundamental: levantamento de teses e dissertações. 2013. 138 f. Dissertação (Mestrado) - Mestrado em Educação, Faculdade de Ciências e Tecnologia, Universidade Estadual Paulista. Presidente Prudente, 2013.

GOMES, M. A. O. O manifesto dos pioneiros da educação nova e a defesa da ordem: o embate entre liberais e católicos no campo da educação. Revista Histedbr On-line, Campinas, v. 16, n. 68, p.109-124, jun. 2016.

HALLEWELL, L. O livro no Brasil: sua história. São Paulo: T. A Queiroz, Edição da Universidade de São Paulo, 1985.

JULIA, D. A cultura escolar como objeto histórico. Revista Brasileira de História da Educação. Campinas, SP, n. 1, 2001, p. 9-43.

MATTOS, R. A. L. Jogo e matemática: uma relação possível. 2009. 157 f. Dissertação (Mestrado) - Mestrado em Educação, Universidade Federal da Bahia, Salvador, 2009.

MOURA, M. O. de. A série busca no jogo: do lúdico na Matemática. In: KISHIMOTO, T. M (organizadora). Jogo, Brinquedo, brincadeira e a educação. 3 ed. São Paulo: Cortez, 1999.

SANTOS, T. M. Metodologia do ensino primário - $3^{a}$ ed., v. 10. São Paulo: Companhia Editora Nacional, 1952. 
SANTOS, T. M. Manual do professor primário $-5^{a}$ ed. São Paulo: Companhia Editora Nacional, 1960.

SANTOS, T. M. Noções de didática especial. São Paulo: Companhia Editora Nacional, 1960.

SCHUBRING, G. Análise histórica de livros de matemática: notas de aula. Tradução de Maria Laura Magalhães Gomes. Campinas, SP: Autores Associados, 2003.

SILVA, V.B. Uma história de leitura para professores - análise na produção e circulação de saberes especializados nos manuais pedagógicos (1930-1971). Revista Brasileira de História da Educação, Maringá/PR, n.6, p. 29-57, jul./dez. 2003.

SMOLE, K. S.; DINIZ, M. I.; CÂNDIDO, P. Resolução de Problemas. Coleção: Matemática de 0 a 6. Porto Alegre: Artmed, 2000.

TOLEDO, M. R. A. A indústria de livros, a materialidade do impresso e o campo educacional: reflexões sobre a organização do acervo histórico da Companhia Editora Nacional. In: Congresso Brasileiro de História da Educação, n.3, 2004. PUCPR. Anais do III Congresso... 2004.

VALENTE, W, R. História da Educação Matemática: interrogações metodológicas. REVEMAT- Revista Eletrônica de Educação Matemática. v. 2, p.28-49, UFSC, 2007.

VALENTE, W. R. Livro didático e educação matemática: uma história inseparável. ZETETIKÉ, Cempem - FE, Unicamp, v.16, n. 30, jul./dez. 2008.

VALENTE, W. R. Oito temas sobre história da educação matemática.

REMATEC, Natal, n.12, p. 22-50, jan./jun. 2013.

VIÑAO FRAGO, A. Sistemas educativos, culturas escolares e reformas. Lisboa: Edições Pedago, 2007.

ZIMMER, I. BOLDO, C. M. S.; COSTA, D. A. Vamos estudar? (1965): A cartilha de Theobaldo Miranda Santos. In: Encontro Nacional de Educação Matemática, 2013, Curitiba, Paraná. Anais... Curitiba: Pontifícia Universidade do Paraná, 2015.

Recebido em: 16 de agosto de 2018 Aprovado em: 15 de janeiro de 2019 